\title{
The complexities of translating legal terms: Understanding Fa (法) and the Chinese concept of law
}

Edition 6, 2021

Lachlan Thomas-Walters

DOI: 10.37839/MAR2652-550X6.18

'The features of law in a given society and at a particular historical stage are shaped not only by the prevailing environment of that time, but also by the cultural heritage of that society, though the role of culture and tradition in shaping the law may be muted, implicit and even unconscious'.

This article explores the relationship between $f a$ (法) and law and argues that the cultural, social, and historical characteristics of the two terms make translation problematic.

Although the modern use of $f a$ in China overlaps significantly with law, this article seeks to show that the denotation of $f a$ is considerably narrower than law. By analysing the complex development of $f a$, it will be argued the differences between the Western concept of law and the Chinese concept of $f a$, are such that translation of $f a$ to law can be misleading in certain contexts, and exacerbate cultural, societal and legal misunderstanding.

\section{Western notions of law}

The term 'law' in western jurisprudence has a multitude of definitions; however, in its broadest sense it encapsulates ideas of justice, righteousness, nature, morality, fairness, order, equity, obligation, codification, rules, reason etc. The Roman word 
jus is often translated to law and captures legal and ethical notions of right and justice. Ancient Roman scholar Cicero described 'Law [as] the highest reason, implanted in nature, which commands what ought to be done and forbids the opposite'. Law has continued to form the foundation of western society, with many jurists touting law as the reason for the preservation of social order, the bastion of harmonious rule, and the very object which stands between morality and humankind's hedonistic inclination for chaos and destruction. British historian and jurist Sir Henry Maine argued that humanity's natural gravitation to the law is fundamental to the formation of society and vital in lifting humanity from the shackles of the primitive.

Western jurisprudence has long held the intrinsic duality of law and morality, with many natural law theorists conceptualising law and morality as being virtually inseparable. Thus, not only does the western conception of law in the positive sense represent rules promulgated by a higher authority to govern society, it also forms the moral compass of humanity; informing right and wrong, codifying ethics, and enshrining principles of righteousness and justice. In contrast, commentators have noted that China has 'traditionally held the law in low esteem' and never viewed legal rules as sacrosanct, or as the ethical and moral basis upon which society should be established. These assumptions of Chinese legal theory led early commentators, such as French jurist and philosopher Montesquieu, to mistakenly describe China as 'a despotic state, whose principle is fear'.

\section{Chinese legal tradition and the etymology of Fa}

Chinese law can be traced back as far as 2700 B.C, and has had a lasting impact on Asian legal systems. The obstacles in comparative studies between Chinese and Western legal systems are most eloquently stated by Xin Ren, who argues the complexity of more than 2,000 years of classical Chinese literature and differences in legal texts are such that academic enquiry is plagued with methodological issues, 
erroneous conclusions, presuppositions, inadequate translation and misunderstanding: 'formidable difficulties...such as the equivalent meaning of a legal term, the synonymous meanings of multiple terms, and the lack of equivalent and appropriate words in Western languages to translate a legal concept precisely'.

The ancient character for $f a$ (法), 滹, is interesting for several reasons and can help to understand some of the key differences between the scope of both fa and law. The character can be analysed by splitting it into its written components. For instance, the left part $\dot{\xi}$ is the radical (a graphical component of a Chinese character) meaning water, while the right side is a combination of the character廌 (zhi) referring to the mythical animal xiezhi 解廌, famous for its ability to determine guilt or innocence, and the character 去 $(q u)$ meaning to go or 'to remove'. The earliest known definition of 湄 $(f a)$ is found in the ancient Han dynasty Shuo-wen dictionary 说文解字 (A.D. 100) where the character is described as:

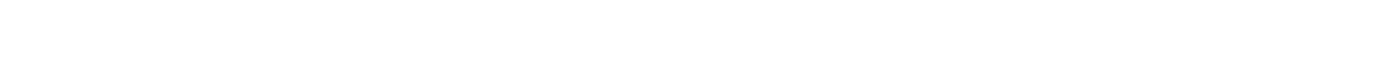

'Fa: was punishment, leveled as even as water, zhi would strike those who are not upright and remove them'

It is generally accepted that the radical for water, found in the classical character of $f a$, connotes the idea of equality before the law; however, renowned Chinese jurist Cai Shuheng argued the interpretation was 'erroneously added by unlearned men of later generations' and is unreliable in forming the basis of etymological understanding. Congruently, Liang contends that the 'the meaning of water is not symbolic but purely functional', and was added to reflect the ancient punishment of exile which would involve criminals being placed on water and left to float downstream. Thus, fa as a legal concept did not encompass concepts of ethics or legal norms, but rather placed emphasis on punishment.

Dutch scholar Hulsewe in his translation of Qin Dynasty legal codes ( $3^{\text {rd }}$ Century B.C.), argued the character $f a$ (法), in some contexts, was almost certainly a loan 
word for fei (废) meaning to 'remove from office', as he argues fa, meaning 'law or norm', did not appear in Qin Dynasty legislation. Indeed, throughout imperial China, the concept of $f a$ is intrinsically linked to punishment or xing (刑). This is substantiated by Chinese legal scholar Tao Xipu who contends that criminal law and civil law were virtually indistinguishable in the ancient law of obligations, and aligns with many Western scholars who place emphasis on the penal nature of early Chinese law. Amongst such scholarship is renowned sinologist Benjamin Schwartz, who writes 'as a supplementary means for social control the word fa (law) is more a synonym of the word punishment, with its first and primary meaning as penal law'. This distinction is important for a number of reasons. First, it tends to substantiate $f a$ as a legal concept inextricably linked to punishment, with rules established to maintain social order. Second, unlike the Western notion of law, fa traditionally did not encapsulate nature, morality, ethics, and justice, but was rather the legal term used for rules which formed objective standards of conduct.

\section{Figure 1: Fa and associated terms}

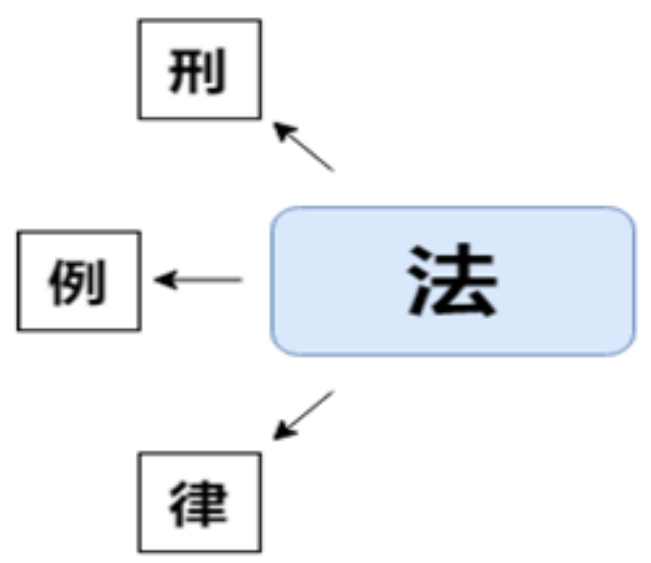

Figure 1, though not an exhaustive list of associated terms, shows how fa is not only connected to the idea of xing (刑), but also denotes the meaning of lü (律, statute), and $l i$ (例, subsidiary rules and regulations). 


\section{Legalist influence on Fa: Narrow in both denotation and application}

As compared to the Western notion of law, fa as a legal concept is considerably narrower in both application and denotation. $\mathrm{Fa}$ has been described by sinologists Derk Bodde and Clarence Morris as 'a generic term for positive or written law as an abstraction...fa is a model or standard imposed by superior authority, to which the people must conform'. While fa connotes a set of rules promulgated by a ruler, a system of governance and civil obedience, as well as a set of punishments designed to control 'man's selfish nature', this only forms part of a complex linguacultural puzzle. Nowadays, $\mathrm{fa}$ is most commonly translated to law, however this can be misleading as several Chinese legal concepts found in jurisprudence and philosophy, namely, Legalism and Confucianism, are intertwined to form the basis of Chinese law. As such, fa only forms part of a dense legal riddle. This is eloquently stated by Lee and Lai who write:

'Fa, although it has been translated as "law", is actually much narrower in scope. It is chiefly associated with the Legalist school of Han Fei-tze'

Legalism, or fajia 法家, popularised by the works of Han Feizi (280 B.C.), reached its zenith in the Qin Dynasty. Han Feizi believed in equality before the law and argued for what he called the 'two handles', namely punishment and favour, believing they could be balanced to create social order and control, writing: 'the law no more makes exceptions for men of high station than the plumb line bends to accommodate a crooked place in the wood. What the law has decreed the wise man cannot dispute nor the brave man contest'. As such, Legalists believed in governance through punishment, which led Chinese legal scholars to describe the legalist idea of governance as one of xingzhi (刑治), ruling through a combination of both order and violence. The success of the ruler and the protection of the state depended on harsh punishments, and as such 'condone[d] the subordination of morality to the practical demands of political realities'. Despite the collapse of the Qin Dynasty, the economic 
and political realities of China meant that a strict penal code coupled with administrative law were preserved in subsequent dynasties. While legal codification and a system of punishments was maintained, Hulsewe notes how 'the theory of government became confucianised...the positive rules of Confucianism reinterpreted in a moral sense became the guiding principles of the state'. Thus, though the legal concept of $f a$ continued to influence the idea of Chinese law, the definition and application of the term $f a$ only encompasses a small part of Chinese law.

\section{The impact of Confucianism}

As scholars such as Burton Watson have colourfully argued, classical Legalist and Confucian conceptualisations of law were so diametrically opposed that they were 'utterly unreconcilable...whirl[ing] about in space like fiercely opposing windmills'. In fact, the Confucian idea of law and morality would come to dominate ancient Chinese legal codes and have a lasting influence on Chinese law today. Thus, any analysis of the Chinese concept of law would be incomplete without discussing the interaction between the Legalist concept of $f a$ (法) and the Confucian concept of $l i$ (礼).

The writings of Confucius have undoubtedly had a profound impact on the development of Chinese culture, society, ethics, and law. Confucius believed that adherence to li was the basis upon which people should be regulated, and the most powerful mechanism for cultivating virtue and creating a harmonious and moral society. Li has been translated as courtesy, virtue, propriety, rites, ritual, and even law, and was 'a code of conduct [and] the just and benevolent methods by which government should be conducted'. Many scholars compare li to notion of 'natural law', describing it as a theory of 'natural li' whereby ethical principles, rather than punishment, would form the basis of ethical society, human interactions, family relations, and governance. Confucius in The Analects writes:

道之以政, 齐之以刑, 民免而无耻; 道之以德, 齐之以礼, 有出版物且格 
'Govern the people by regulations, keep order among them by chastisements, and they will flee from you, and lose all respect. Govern them by moral force, keep order among them by ritual [li] and they keep their self-respect and come to you of their own accord.

Scholar Tung-Tsu Chu argues that the single most significant legal development in China before the $20^{\text {th }}$ Century was the 'Confucianization of the law'; despite the seemingly incongruent nature of $l i$ and $f a$ they would combine to form the foundation of Chinese law, as the enforcement of li was 'simultaneously sustained by both social and legal sanctions'. Therefore, Chinese history of legal codification can be categorised by the continued symbiosis of both li and fa with Tang, Song and even the Mongol Yuan Dynasty maintaining Confucian values and norms in legal instruments. The long-lasting nature of China's dynastic legal codes led leading scholars such as Brian McKnight to argue that the continuity and success of codification was in the effective balance of both substantive and procedural law, as well as the underlying normative justification of rules. Therefore, as Chinese law continued to develop fa only occupied a part of law in China.

\section{The concepts of law: a complex ideological puzzle}

Legalist and Confucian ideology continues to influence the Chinese concept of law and justice. Australian scholar Delia Lin, argues how the Chinese concept of yi (义), or justice, in China can be split into 'High Justice' and 'Low Justice'. High Justice being the moral supremacy of the ruler, and Low Justice being the fair treatment of the people. Lin claims that $f a$ is separate from the idea of justice. Figure 2 shows a non-exhaustive list of words which interact to form the central ideas of Chinese law. 


\section{Figure 2: The concepts of Chinese law}

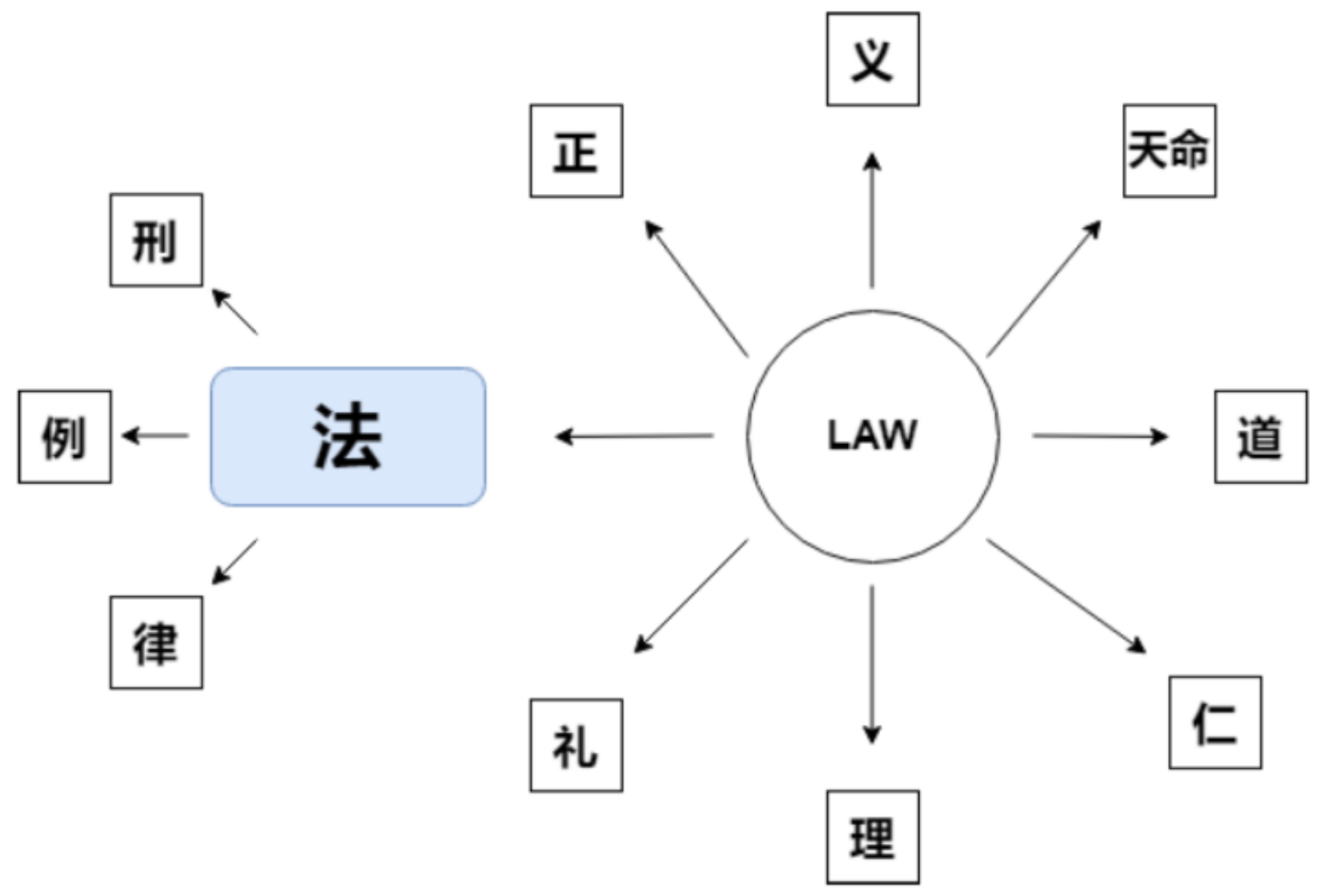

Figure 2, though not an exhaustive list, serves to exemplify how $f a$ and its associated concepts, namely codified legal rules (律,例) and punishment (刑), only form part of an intricate and complex array of ideas which combine to inform the Chinese concept of law. As is demonstrated above, fa only occupies a part of what makes up Chinese law.

The denotative meaning of $f a$ is considerably narrower than law. As such, I contend that uncritically translating fa directly to law may fail to recognise the complexity of Chinese jurisprudence, and may lead to social, cultural and legal misunderstanding.

It is hoped that through utilising the field of translation to shed light on the significant conceptual and denotative differences between fa and law, this article 
may help overcome translation problems arising out of cross-cultural and interdisciplinary misunderstanding. More research is needed in the field of translation to help identify the extent to which terminological barriers hamper comparative legal study between China and the West.

Image: Xi'an City Wall at dusk, 2011. Credit: Jack Zalium/Flickr 